\title{
Microstructural Characterization of Reaction-Formed Silicon Carbide Ceramics
}

M. Singh and T.A. Leonhardt NYMA, Inc.

Lewis Research Center Group

Cleveland, $\mathrm{OH} 44135$

Materials Characterization

April 1995 


\title{
Microstructural Characterization of Reaction-Formed Silicon Carbide Ceramics
}

\author{
M. Singh and T.A. Leonhardt \\ NYMA, Inc. \\ Lewis Research Center Group \\ Cleveland, $\mathrm{OH} 44135$
}

\begin{abstract}
Microstructural characterization of two reaction-formed silicon carbide ceramics has been carried out by interference layering, plasma etching, and microscopy. These specimens contained free silicon and niobium disilicide as minor phases with silicon carbide as the major phase. In conventionally prepared samples, the niobium disilicide cannot be distinguished from silicon in optical micrographs. After interference layering, all phases are clearly distinguishable. Back scattered electron (BSE) imaging and energy dispersive spectrometry (EDS) confirmed the results obtained by interference layering. Plasma etching with $\mathrm{CF}_{4}+4 \% \mathrm{O}_{2}$ selectively attacks silicon in these specimens. It is demonstrated that interference layering and plasma etching are very useful techniques in the phase identification and microstructural characterization of multiphase ceramic materials.
\end{abstract}




\section{INTRODUCTION}

In recent years, there has been a surge of interest in research and development of high performance advanced ceramics and ceramic matrix composites for a variety of aerospace and terrestrial applications. A number of these applications require materials with good strength and toughness, high thermal conductivity and good environmental stability at high temperatures. Silicon carbide based advanced ceramics have attracted a great deal of attention for application in gas turbine components, heat exchangers, mechanical seals, and wear parts [1-4]. However, silicon carbide based monolithic ceramics can contain processing and machining induced flaws which may lead to failure of components manufactured from these materials. Metallography can play a critical role in the evaluation of flaws, porosity, and the distribution of secondary phases. Critical examination of microstructural information along with mechanical property data can guide modification of the material fabrication process to obtain optimum mechanical properties.

In the microstructural examination of high performance 
ceramics, optical methods of contrast, such as dark field illumination, polarized light and phase contrast, are only of limited use. Some chemical treatments like etching are needed to enhance the contrast. The etching of ceramic materials with molten salts has to be carried out at temperatures as high as $400^{\circ} \mathrm{C}$ due to their excellent resistance to chemical attack. Recently, Carle et al. [5-6] described various issues and concerns with chemical and physical etching methods. Often, the grain boundaries are etched preferentially and small grains are completely etched out. In addition, these chemicals are very aggressive in concentrated form and have to be used at boiling temperatures, which requires stringent safety precautions. Interference layering and plasma etching techniques overcome a number of these problems [7-11].

Interference layering has been used for the enhancement of phase contrast in a number of materials [7]. For example, unreacted carbon can easily be distinguished from residual porosity. Also, interference layered microstructures often have sufficient contrast for the application of automated quantitative metallographic techniques. In this technique, a platinum $(\mathrm{Pt})$ or lead $(\mathrm{Pb})$ target is used to 
sputter-coat in an oxygen atmosphere to form a thin layer of $\mathrm{PtO}_{2}$ or $\mathrm{PbO}_{2}$ on the sample [7-8]. These oxide layers change the sample's reflection coefficient. Since each phase has a different reflection coefficient, each gives rise to a different color which enhances the contrast.

In the plasma etching technique, a reactive gas, such as $\mathrm{CF}_{4}$, is used as an etchant to produce volatile species by reaction with silicon or silicon containing materials [9-11]. The high reactivity of $\mathrm{CF}_{4}$ plasma is related to the formation of $\mathrm{CF}_{\mathrm{x}}{ }^{+}$ions. This technique has several advantages over other chemical etching techniques. The specimen temperature is not very high during the process $\left(\sim 85^{\circ} \mathrm{C}\right)$, which is considerably lower than the temperature used for molten salt etching $\left(\sim 400^{\circ} \mathrm{C}\right)$. Also, plasma etching can be performed on a selected portion of a sample by covering the rest of the surface with a heat resistant tape. In addition, selected constituents can be etched out to evaluate the distribution and morphology of various phases in materials.

The purpose of this paper is to document the procedures used 
for sample preparation and microstructural examination of silicon carbide based ceramic materials containing silicon and niobium disilicide phases using the above techniques. Interference layering, plasma etching, and scanning electron microscopy coupled with energy dispersive $\mathrm{x}$-ray analysis techniques have been used in this study. A clear description of the microstructural features and their interpretation is presented.

\section{EXPERIMENTAL PROCEDURES}

The reaction-formed silicon carbide materials used in this study were fabricated using a reaction forming process where a microporous carbon preform was infiltrated with molten silicon or a siliconniobium alloy. The final product of silicon infiltration and reaction was silicon carbide with a controllable amount of residual silicon. In the case of silicon-niobium alloy infiltration, the final product was silicon carbide with niobium disilicide and free silicon. The fabrication details of these materials have been described elsewhere [1-4].

Metallographic preparation of polished specimens began with 
mounting in a two part epoxy, followed by vacuum degassing and curing for $12 \mathrm{hrs}$. Subsequent grinding and polishing steps are given in Table 1. To produce the interference film, a metallic target (usually a third row transition metal), which is a thin sheet $0.25 \mathrm{~mm}$ thick $\times 54$ $\mathrm{mm}$ in diameter, is used. In this study, a lead $(\mathrm{Pb})$ target was sputtered in an oxygen atmosphere to form a thin layer of $\mathrm{PbO}_{2}$ on the surface of the sample. A list of the parameters used are given in Table 2. These parameters produce an interference layer that is translucent and is approximately $500 \mathrm{~A}^{\circ}$ thick.

During plasma etching, a benign gas $\left(\mathrm{CF}_{4}+4 \% \mathrm{O}_{2}\right)$ is pulled through a gas control systems and into a vacuum chamber encircled by a radio frequency $(R F)$ coil operating at $13.56 \mathrm{mHz}$. The plasma etching system used is shown in Fig. 1 and parameters of operation are given in Table 3. The RF coil causes electric discharges in the gas which lead to cracking of the gases into reactive fragments $\left(C_{x}\right)$ which attack silicon-based materials to form $\left(\mathrm{SiF}_{\mathrm{x}}\right)$ compounds which have a low vapor pressure. Further details of this process has been described elsewhere [11]. During plasma etching, the decomposition processes of $\mathrm{CF}_{4}+\mathrm{O}_{2}$ base gases and the reaction of silicon and 
carbon with $\mathrm{CF}_{4}$ plasma is given as follows [14]:

$$
\begin{aligned}
& \mathrm{CF}_{4}+\mathrm{O}_{2} \rightarrow \mathrm{CF}_{x}+\mathrm{F}^{-}+\mathrm{O}+\left(\mathrm{CO}, \mathrm{CO}_{2}\right) \\
& \mathrm{Si}+4 \mathrm{~F} \rightarrow \mathrm{SiF}_{4} \\
& \mathrm{C}+\mathrm{xF} \rightarrow \mathrm{CF}_{x} \\
& \mathrm{C}+x \mathrm{O} \rightarrow\left(\mathrm{CO}, \mathrm{CO}_{2}\right)
\end{aligned}
$$

After preparation, samples were examined in an optical microscope (bright field). As polished and plasma etched samples were also examined in a scanning electron microscope using the backscattered and secondary electron imaging modes to confirm the optical results.

\section{RESULTS AND DISCUSSION}

\section{As Polished Cross-Sections:}

The as polished microstructures of reaction-formed silicon carbides containing free silicon, and silicon and niobium disilicide 
phases are given in Figs. 2 (a) and (b), respectively. These micrographs show the uniformly distributed secondary phases throughout the material. In Fig. 2 (b), it is very difficult to distinguish silicon from niobium disilicide. This clearly indicates that bright field illumination is not sufficient for differentiation between silicon and molybdenum disilicide or niobium disilicide phases. The following discussion on the application of interference layering and microscopy will focus on these two material systems.

\section{Interference Layered Microstructure:}

Micrographs of the interference layered reaction-formed silicon carbide materials containing free silicon and silicon and niobium disilicide phases are given in Figs. 3 (a) and (b), respectively. In Fig. 3 (a), the dark brown areas are silicon carbide and orange areas are free silicon. In Fig. 3 (b), the dark red areas in the micrograph are free silicon and grey areas are niobium disilicide. The niobium disilicide and silicon are uniformly distributed throughout the silicon carbide 
matrix. Interference layering not only increases optical contrast, but also can illustrate different constituents, as shown in Fig 3. There is no porosity in either of these materials.

The interpretation of the color differences in the interference layered micrographs were confirmed by backscattered SEM images and EDS characterization of several regions in these materials. Figs. 4 (a) \& (b) are backscattered electron micrographs of the silicon and niobium disilicide plus silicon containing materials. In Fig. 4(a), white areas were found to correspond to silicon and dark grey areas to silicon carbide. The black areas are unreacted carbon. The contrast in these images is due to variation in the average atomic number. The EDS spectra from the above regions are given in Figs. 5 (a)-(c) to confirm the BSE results.

A backscattered electron micrograph of niobium disilicide plus free silicon containing material is given in Fig. 4(b). In this image, white areas were found to be niobium disilicide, light grey was 
silicon, dark grey was silicon carbide, and black was unreacted carbon. These regions were further analyzed in EDS and the spectra from the above regions are given in Fig 6 (a)-(c). The backscattered imaging and EDS analysis confirm the results of interference layering technique.

\section{Plasma Etched Microstructure:}

In Figs. 7 (a) and (b), micrographs of the plasma etched specimens containing free silicon, and niobium disilicide plus free silicon, respectively, are presented. Since silicon etches faster than silicon carbide, the areas that contained silicon appear as pores in the micrograph. In Fig. 7(b), both secondary phases (silicon and niobium disilicide) appears to be removed by plasma etching. However, the niobium disilicide etching rate appears to be slower than that of free silicon [15]. A higher magnification scanning electron micrograph of plasma etched RFSC material is given in Fig. 8. This micrograph shows some facetting of the silicon carbide grains and the variation 
of grain sizes. More detailed characterization of the microstructure and grain growth in these materials is underway and will be reported elsewhere [15].

\section{SUMMARY OF RESULTS}

Microstructural characterization of reaction-formed silicon carbide ceramics by the techniques of interference layering, plasma etching and scanning electron microscopy/energy dispersive $x$-ray analysis revealed that specimens contained free silicon and niobium disilicide as minor phases with silicon carbide as the major phase. In conventionally prepared samples, niobium disilicide cannot be distinguished from silicon in optical micrographs. In interference layered samples, all phases are clearly distinguished. Plasma etching with $\mathrm{CF}_{4}+4 \% \mathrm{O}_{2}$ selectively attacks silicon from these specimens. It is demonstrated that interference layering coupled with plasma etching are very useful techniques in the microstructural characterization of multiphase ceramic materials. 


\section{CONCLUSIONS}

The microstructures of three reaction-formed silicon carbide ceramics are revealed by interference layering and plasma etching techniques. All microstructural constituents are distinguishable in each specimen. The plasma etched microstructure also revealed some facetting in the structure. The advantages of interference layering and plasma etching over conventional etching in phase identification and microstructural characterization can help guide the successful development of multiphase ceramic materials.

\section{ACKNOWLEDGEMENTS}

The authors would like to thank Ms. Pat Dickerson for her help in the SEM and EDS work and Dr. Rob Dickerson for making valuable comments. 


\section{REFERENCES}

[1] M. Singh and D.R. Behrendt, NASA TM-105860 (1992).

[2] M. Singh and D.R. Behrendt, J. Mater. Res. 9, 7 (1994) 17011708.

[3] M. Singh and D.R. Behrendt, Mater. Sci. Engg., A187 (1994) 183-187.

[4] M. Singh and S.R. Levine, Technology 2004, Washington, DC (1994).

[5] V. Carle, U. Schafer, U. Taffner, F. Predel, R. Telle and G. Petzow, Pract. Met., 28 (1991) 359-377.

[6] V. Carle, U. Schafer, U. Taffner, F. Predel, R. Telle and G. Petzow, Pract. Met., 28 (1991) 421-434.

[7] H.-E. Buhler and H.P. Hougardy, 'Atlas of Interference Layer Metallography', Deutsch Gesellschaft fur Metallkunde, Oberursel, Germany (1980).

[8] W.J. Brindley and T.A. Leonhardt, Materials Characterization, 24, (1990) 93-101.

[9] M. Mitomo, Y. Sato, I. Yashima and M. Tsutsumi, J. Mater. Sci. Lett., 10 (1990) 83-84.

[10] R.W. Kirk, in 'Techniques and Applications of Plasma Chemistry', edited by J.R. Hollahan and A.T. Bell, Wiley, New York, (1974) 349.

[11] D.R. Hull, T. A. Leohardt and W.A. Sanders, NASA TM-105430 (1991).

[12] H. Abe, Y. Sonobe and T. Enomoto, Japan J. Appl. Phys., 12 (1973) 154. 
[13] T.M. Mayer, R.A. Barker and L.J. Whitman, J. Vac. Sci. Technol., 18, 2 (1981) 349-352.

[14] J. Sugiura, W.-J. Lu, K.C. Cadien and A.J. Steckl, J. Vac. Sci. Technol., B4, 1 (1986) 349-354.

[15] M. Singh, unpublished results (1994) 
Table 1 : Details of metallographic preparation of specimens

\begin{tabular}{|c|c|c|c|c|}
\hline $\begin{array}{l}\text { Preparation } \\
\text { Step }\end{array}$ & $\begin{array}{c}\begin{array}{c}\text { Diamond } \\
\text { Abrasive, } \\
\mu \mathrm{m}\end{array} \\
\end{array}$ & Lubricant & Time, $\min$ & Comments \\
\hline $\begin{array}{l}\text { Grinding } \\
\text { (fixed } \\
\text { abrasive) }\end{array}$ & $\begin{array}{l}115 \\
65 \\
20\end{array}$ & $\begin{array}{l}\text { Water } \\
\text { Water } \\
\text { Water }\end{array}$ & $\begin{array}{c}\text { Until planar } \\
2 \\
2\end{array}$ & \\
\hline $\begin{array}{l}\text { Grinding } \\
\text { (nonfixed } \\
\text { abrasive) } \\
\text { Lapping Disk }\end{array}$ & $\begin{array}{l}6 \\
3\end{array}$ & $\begin{array}{l}\text { Ethyl } \\
\text { Alcohol }\end{array}$ & $\begin{array}{l}9 \\
9\end{array}$ & $\begin{array}{l}\text { Copper cross } \\
\text { hatch } \\
\text { Copper spiral }\end{array}$ \\
\hline $\begin{array}{l}\text { Polishing } \\
\text { (diamond } \\
\text { suspension) }\end{array}$ & $\begin{array}{l}3 \\
1\end{array}$ & & $\begin{array}{l}6 \\
4\end{array}$ & $\begin{array}{l}\text { Hard synthetic silk } \\
\text { polishing cloth }\end{array}$ \\
\hline $\begin{array}{l}\text { Final } \\
\text { vibratory } \\
\text { polishing } \\
\text { (diamond } \\
\text { suspension) }\end{array}$ & 0.5 & $\begin{array}{l}\text { Ethylene } \\
\text { Glycol }\end{array}$ & $24 \mathrm{hr}$ & $\begin{array}{l}\text { High nap } \\
\text { synthetic cloth }\end{array}$ \\
\hline
\end{tabular}


Table 2: Process parameters for interference layering with lead $(\mathrm{Pb})$

Power

Gas

Vacuum*

DC bias

Time

Distance

(target to sample)
$55 \mathrm{~mA}$

Oxygen

1 mbar or .75 torr

650 volts

365 second

$2 \mathrm{~cm}$

* The sputtering system used is a MED 010 Balzer unit which has mechanical and turbo vacuum pumps. The ultimate vacuum is $1.0 \times 10^{-4}$ mbar which is then back filled with oxygen to a vacuum of 1 mbar.

Table 3: Experimental parameters for plasma etching

Power

Gas

Vacuum*

Frequency

Time
100 watts

$\mathrm{CF}_{4}+4 \% \mathrm{O}_{2}$

200 mtorr

$13.56 \mathrm{mhz}$

4 hours

* The chamber is pumped down to $1.0 \times 10^{-3}$ torr and then back filled to 200 mtorr. 


\section{Figure Captions}

Fig. 1: Photograph of the plasma etching system

Fig. 2: Optical micrographs of reaction-formed silicon carbide ceramics containing (a) silicon and (b) silicon and niobium disilicide phases.

Fig. 3 : Optical micrographs of reaction-formed silicon carbide ceramics after interference layering, (a) with silicon (orange$\mathrm{Si}$, brown-SiC), and (b) silicon and niobium disilicide phases (red-Si, grey-NbSi, brown-SiC).

Fig. 4: Scanning electron micrographs (BSE) of reaction-formed silicon carbide ceramics (a) with silicon (white-Si, dark grey-SiC, black-C) and (b) silicon and niobium disilicide phases (white-NbSi ${ }_{2}$, light grey-Si, dark grey-SiC, black-C).

Fig. 5: $\quad$ EDS spectra of silicon containing silicon carbide material (a) $\mathrm{Si}$ areas, (b) $\mathrm{SiC}$ areas, and (c) $\mathrm{C}$ rich areas.

Fig. 6: EDS spectra of niobium disilicide and silicon containing silicon carbide material (a) $\mathrm{Si}$ areas, (b) $\mathrm{C}$ areas, and (c) $\mathrm{Nb}$ rich areas.

Fig. 7 : Scanning electron micrographs of reaction-formed silicon carbide ceramics after plasma etching for $4 \mathrm{hrs}$, (a) with silicon, and (b) silicon and niobium disilicide phases.

Fig. 8: Scanning electron micrograph of reaction-formed silicon carbide ceramic showing grain morphology. 
$a$

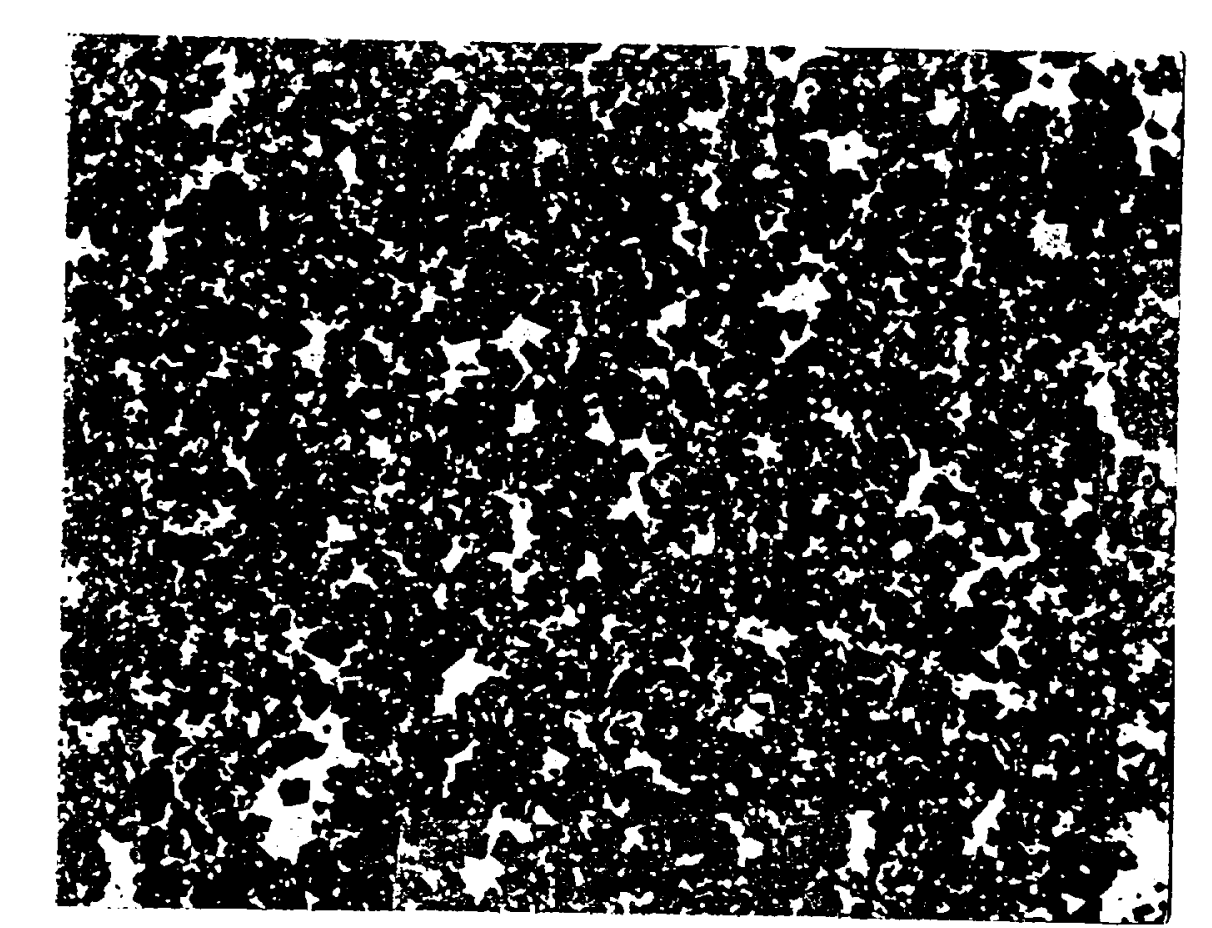

b

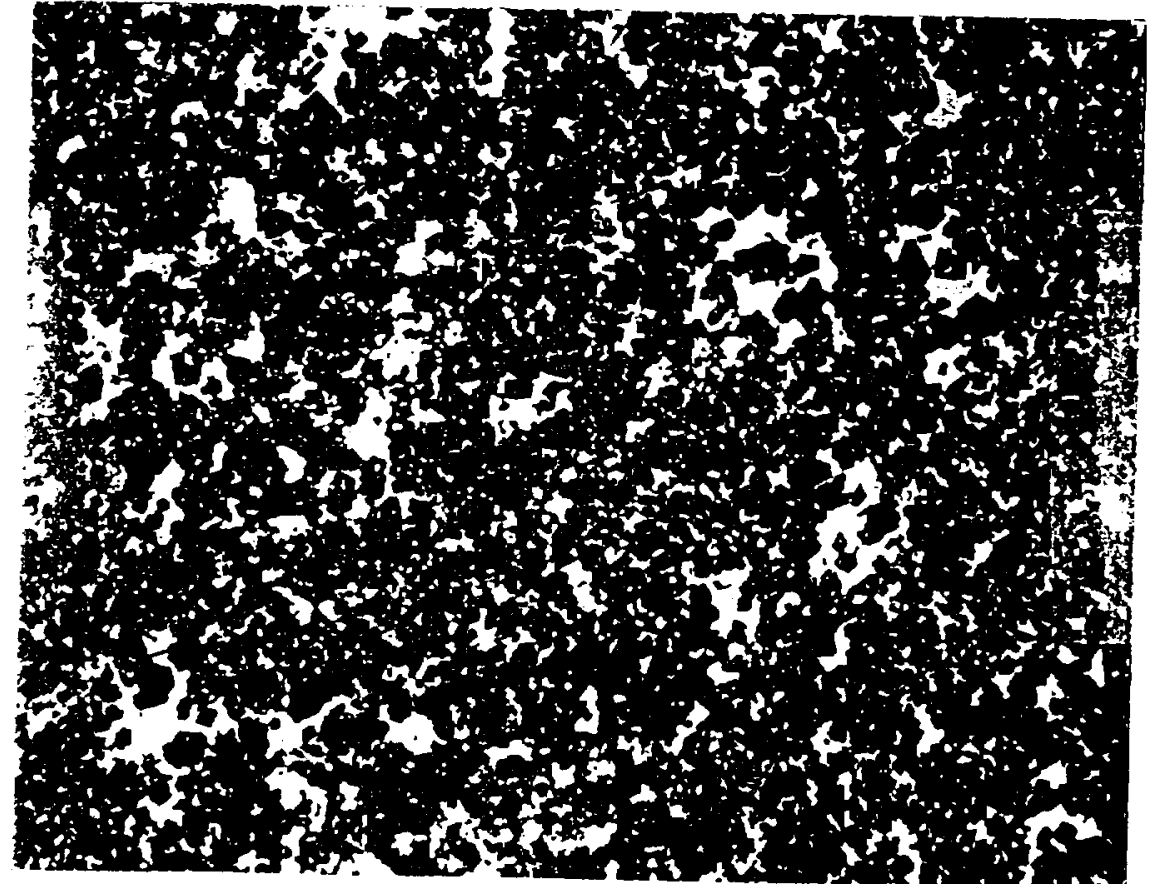

Fin.2

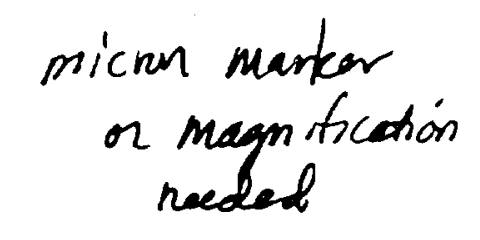


(a)

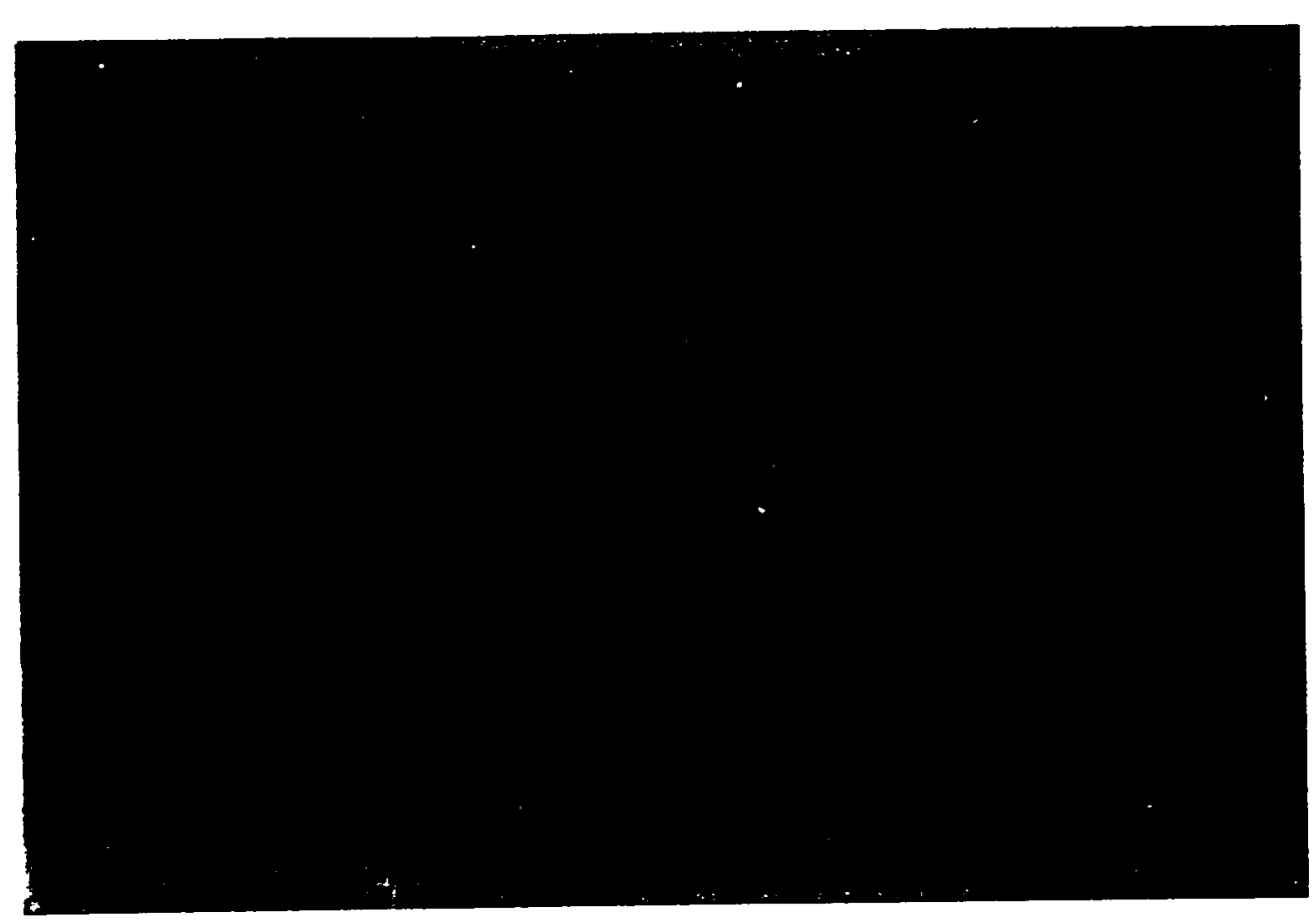

orage- $S$ Brown. Sil

$500^{2}$

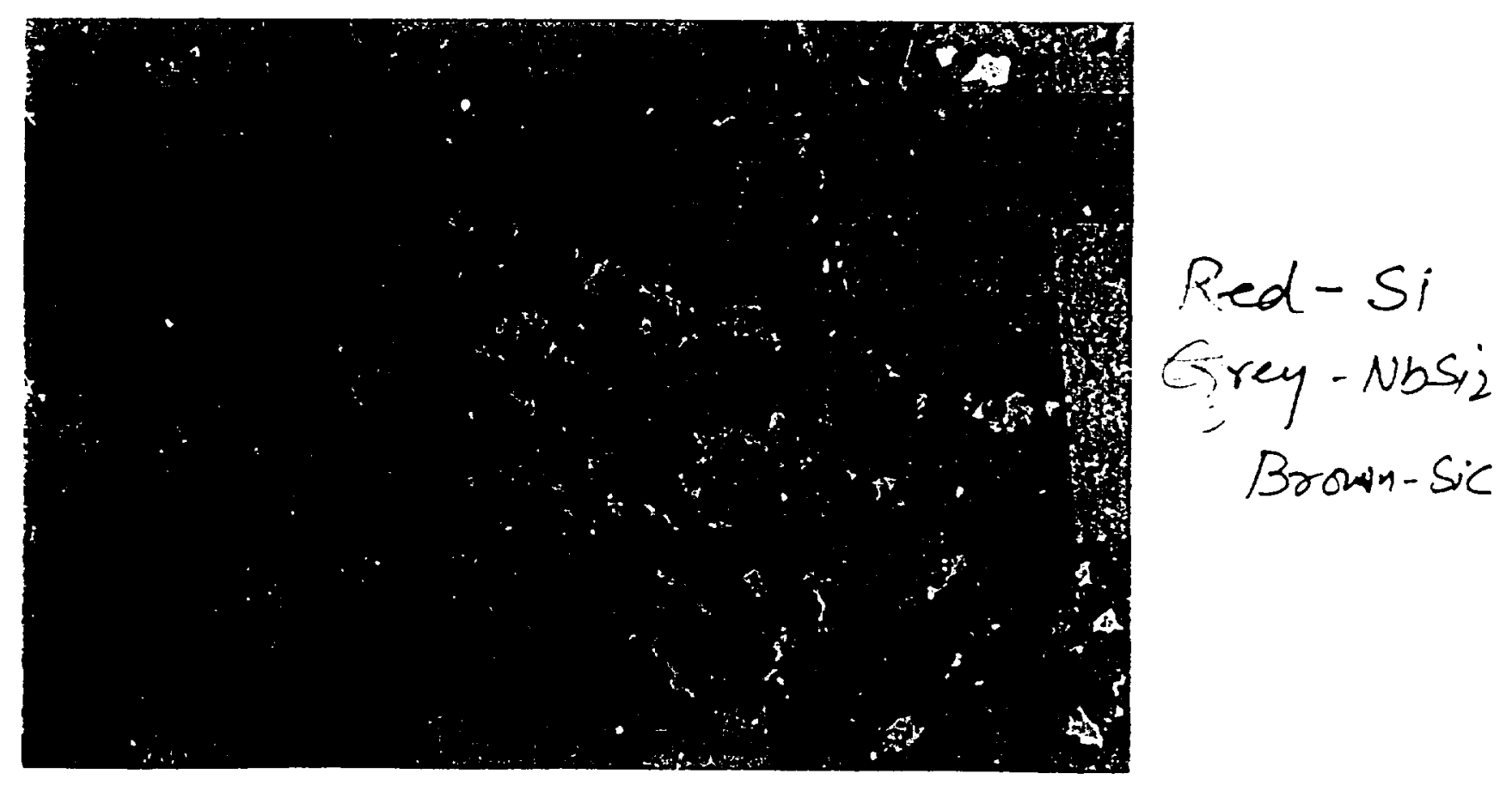

$F r .3$

see comment $f x$ $\alpha_{y} 2$. 
(a)

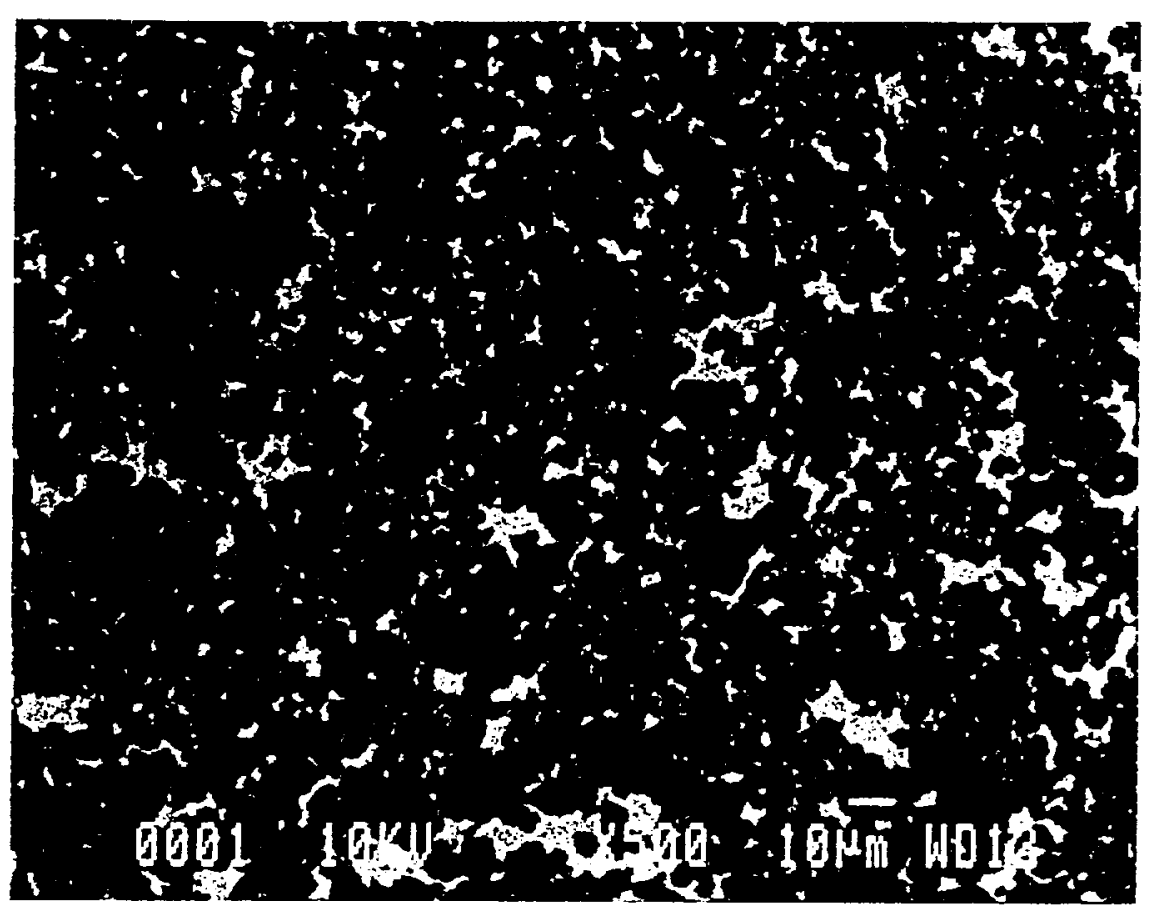

(b)

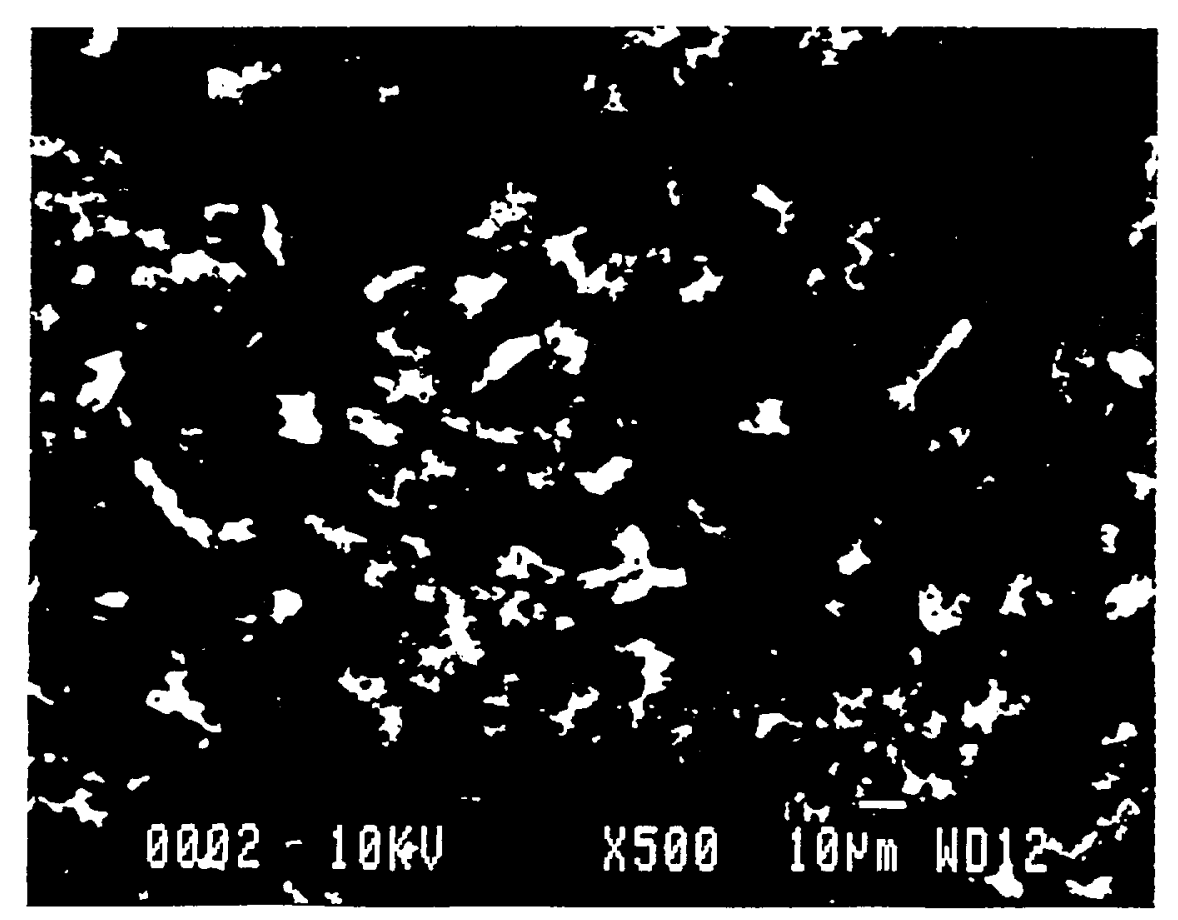

Fegt 

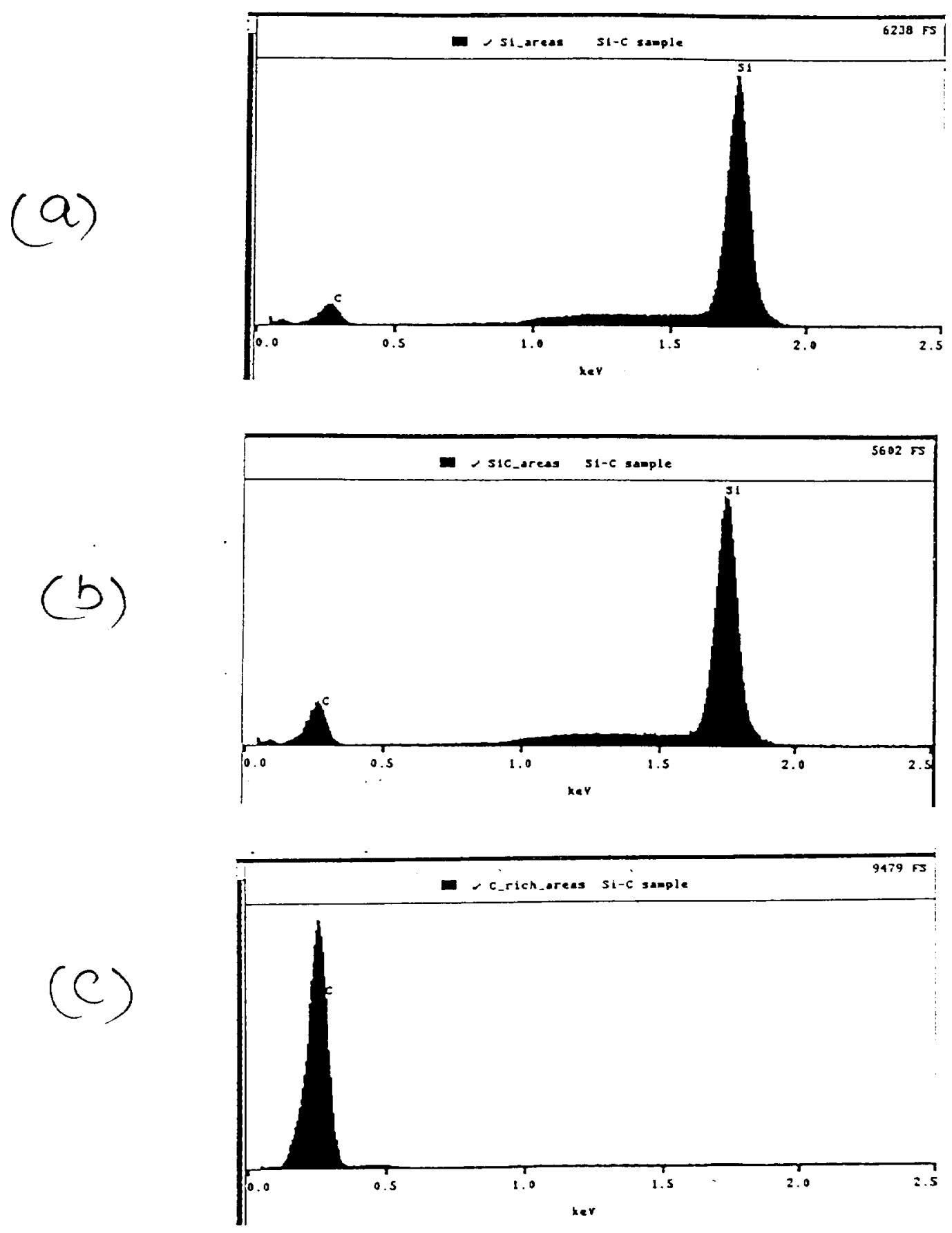

Fes. 5 

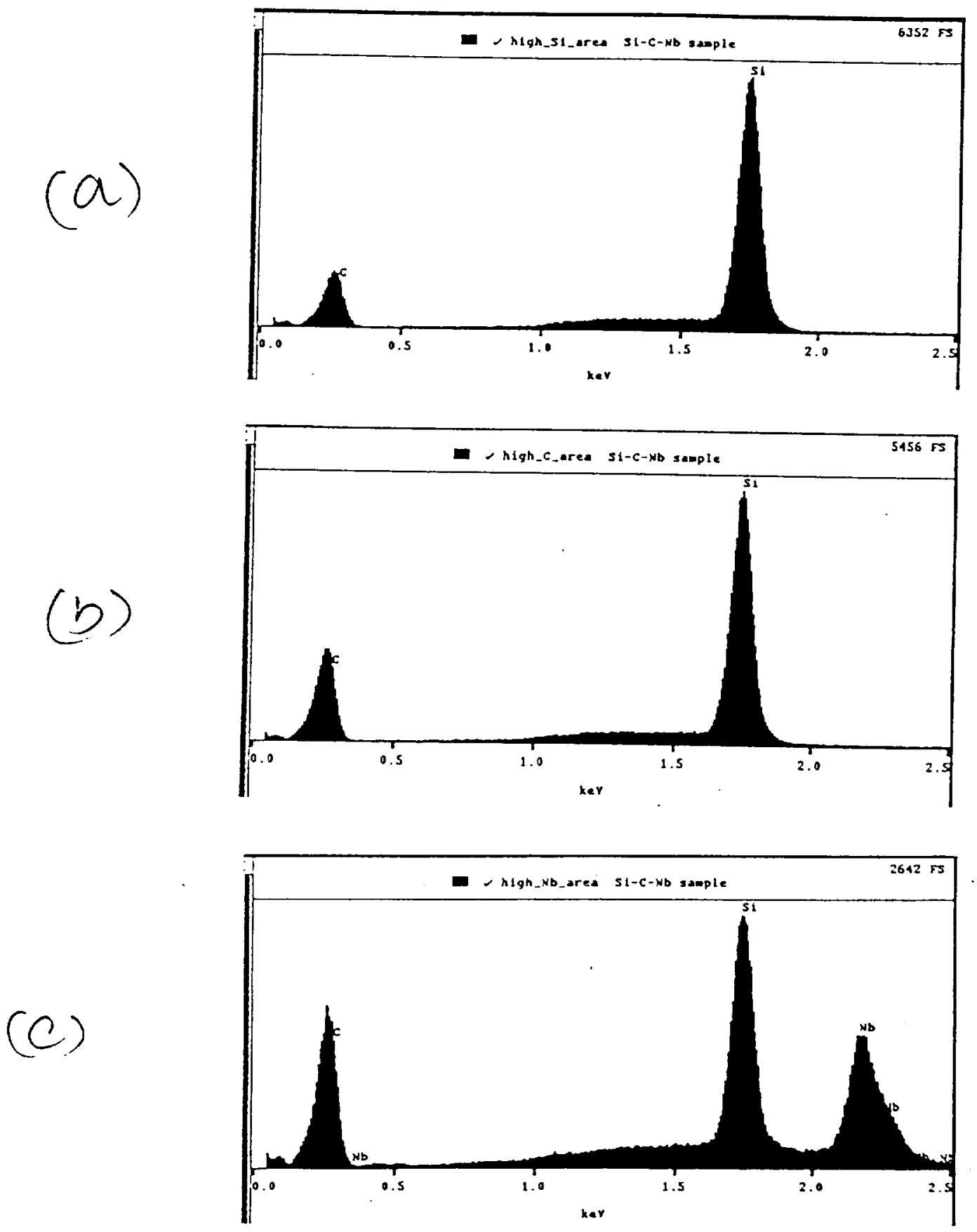

Frs. 6 
(a)

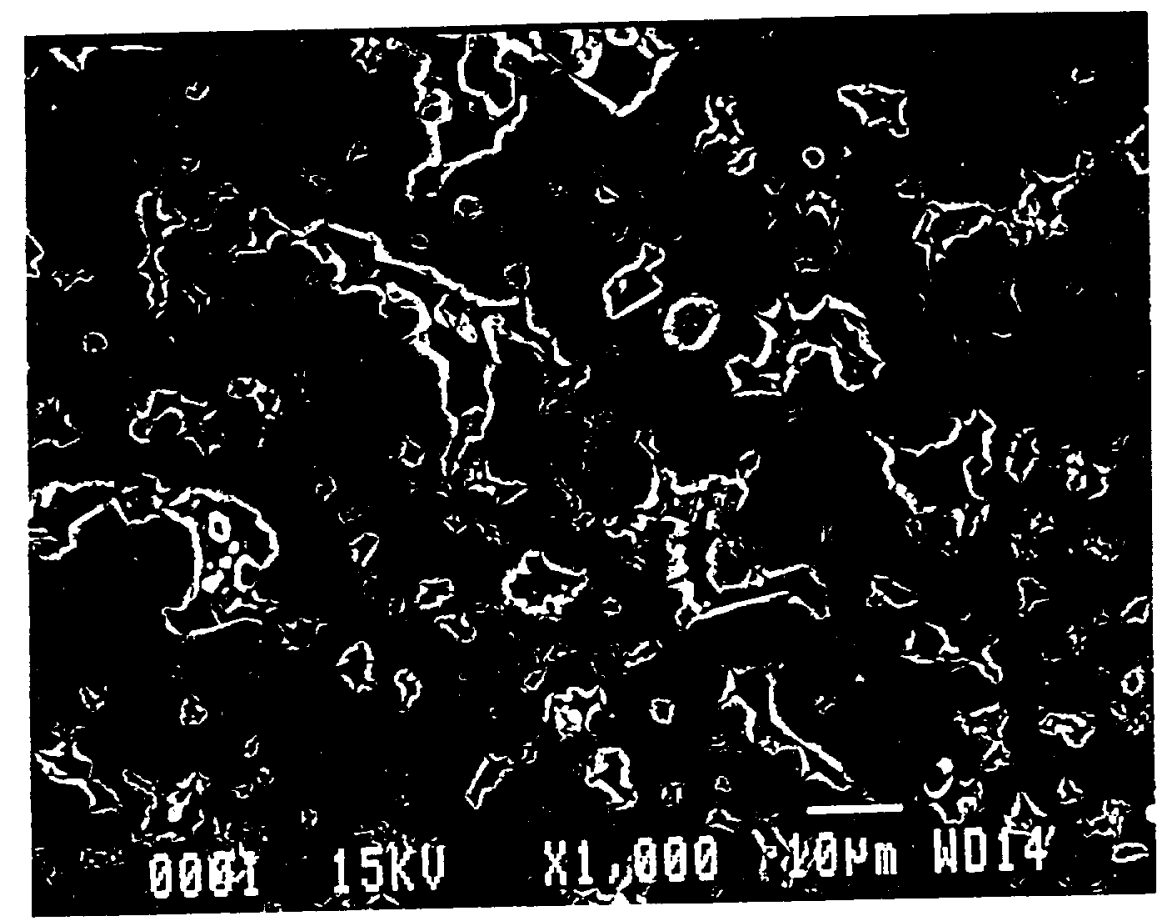

(b)

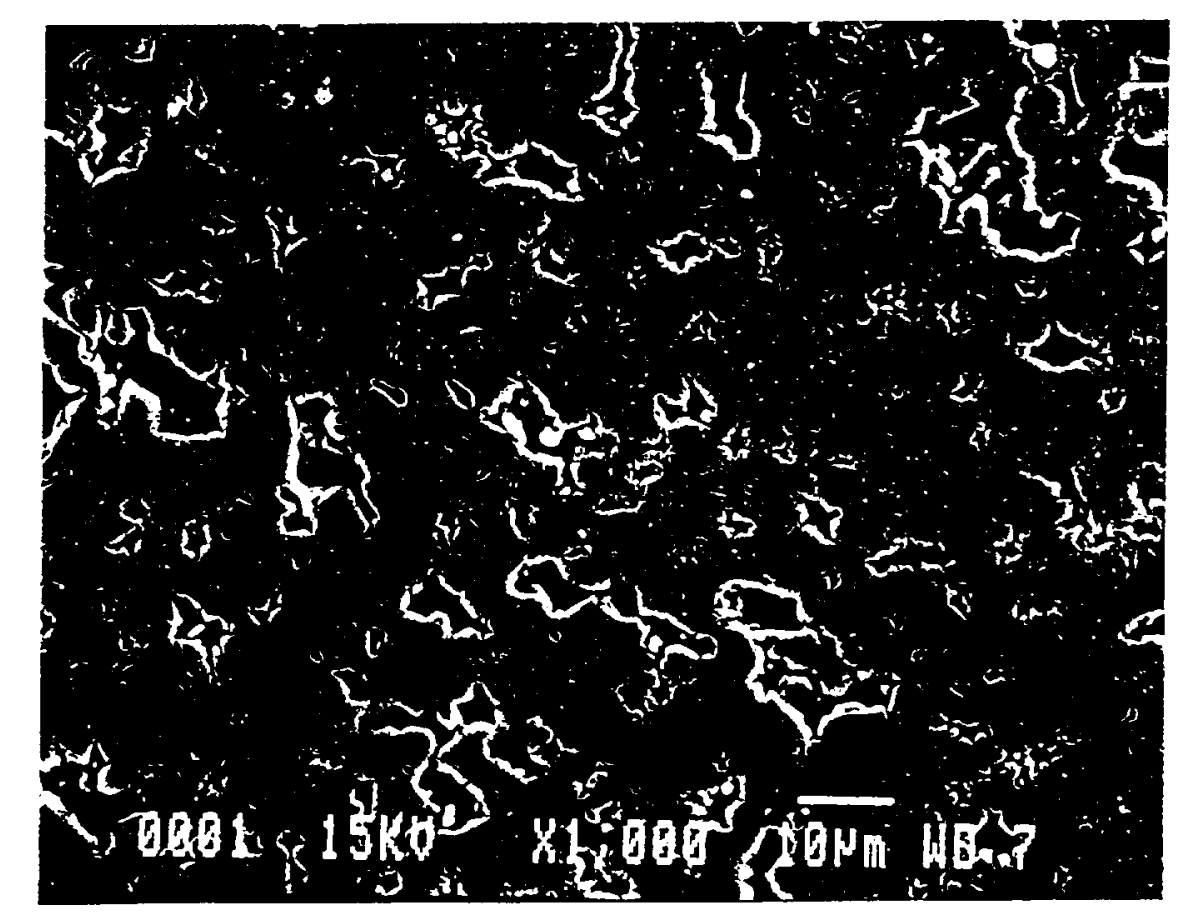

$\operatorname{lig} 7$ 


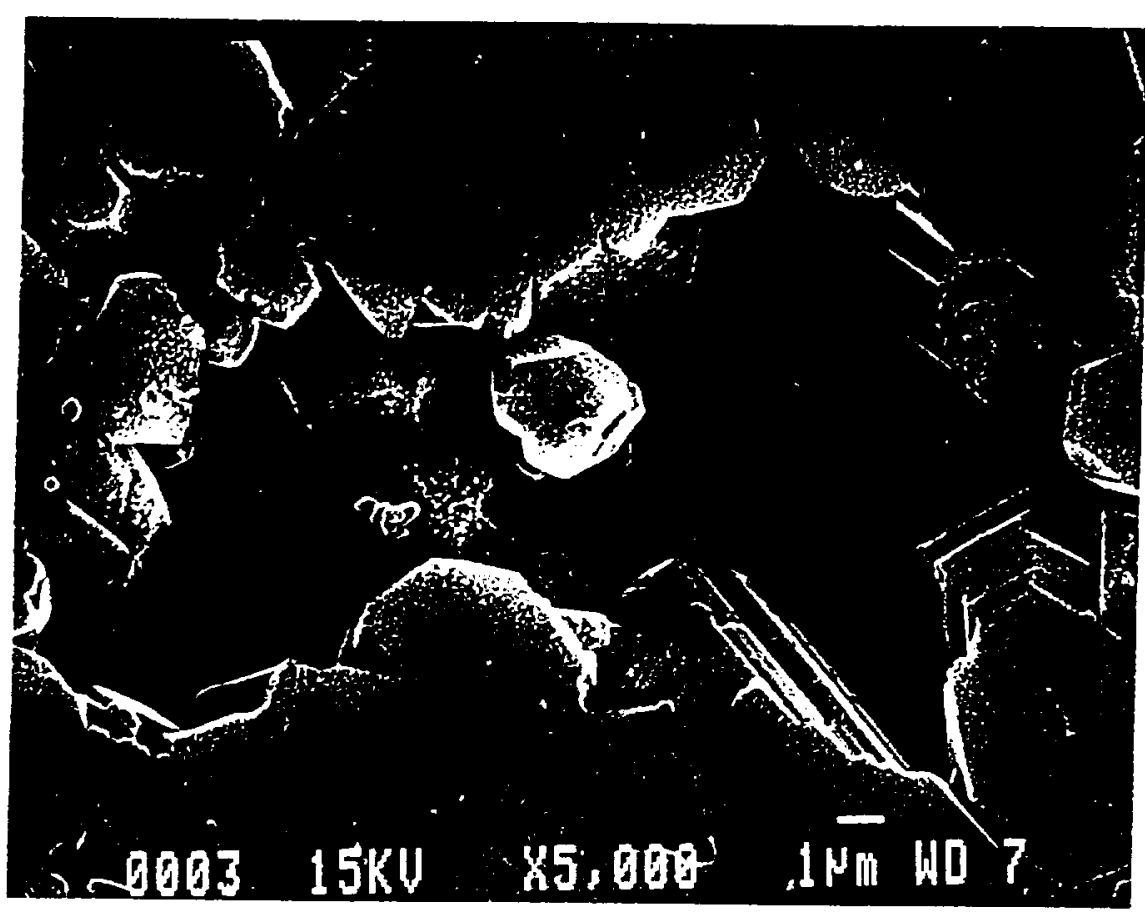

Frs. 8 